\title{
MUC5B silencing reduces chemo-resistance of MCF-7 breast tumor cells and impairs maturation of dendritic cells
}

\author{
ENRIQUE P. GARCÍA ${ }^{1}$, INÉS TISCORNIA ${ }^{2}$, GABRIELA LIBISCH $^{3}$, FELIPE TRAJTENBERG $^{4}$, \\ MARIELA BOLLATI-FOGOLÍN ${ }^{2}$, ERNESTO RODRÍGUEZ ${ }^{1}$, VERÓNICA NOYA ${ }^{1}$, CAROLINA CHIALE ${ }^{1}$, \\ NATALIE BROSSARD ${ }^{1}$, CARLOS ROBELLO ${ }^{3,5}$, FEDERICO SANTIÑAQUE ${ }^{6}$, \\ GUSTAVO FOLLE ${ }^{6}$, EDUARDO OSINAGA ${ }^{7,8}$ and TERESA FREIRE ${ }^{1}$
}

\begin{abstract}
${ }^{1}$ Department of Immunobiology, Immunomodulation and Vaccine Development Laboratory, Facultad de Medicina, UdelaR, CP11800 Montevideo; ${ }^{2}$ Cell Biology Unit, ${ }^{3}$ Molecular Biology Unit and ${ }^{4}$ Unit of Protein Crystallography, Institut Pasteur de Montevideo, CP 11400 Montevideo; ${ }^{5}$ Dept. Biochemistry, Facultad de Medicina, UdelaR, CP11800 Montevideo; ${ }^{6}$ Department of Genetics, Instituto de Investigaciones Biológicas Clemente Estable, CP 11600 Montevideo; ${ }^{7}$ Glycobiology and Tumor Immunology Laboratory, Institut Pasteur de Montevideo, CP 11400; ${ }^{8}$ Department of Immunobiology, Facultad de Medicina, UdelaR, CP11800 Montevideo, Uruguay
\end{abstract}

Received July 29, 2015; Accepted December 16, 2015

DOI: 10.3892/ijo.2016.3434

\begin{abstract}
Mucins participate in cancer progression by regulating cell growth, adhesion, signaling, apoptosis or chemo-resistance to drugs. The secreted mucin MUC5B, the major component of the respiratory tract mucus, is aberrantly expressed in breast cancer, where it could constitute a cancer biomarker. In this study we evaluated the role of MUC5B in breast cancer by gene silencing the MUC5B expression with short hairpin RNA on MCF-7 cells. We found that MUC5B-silenced MCF-7 cells have a reduced capacity to grow, adhere and form cell colonies. Interestingly, MUC5B knock-down increased the sensitivity to death induced by chemotherapeutic drugs. We also show that MUC5B silencing impaired LPS-maturation of DCs, and production of cytokines. Furthermore, MUC5B knock-down also influenced DC-differentiation and activation since it resulted in an upregulation of IL-1 $\beta$, IL- 6 and IL-10, cytokines that might be involved in cancer progression. Thus, MUC5B could enhance the production of LPS-induced cytokines, suggesting that the use of MUC5B-based cancer vaccines combined with DC-maturation stimuli, could favor the induction of an antitumor immune response.
\end{abstract}

Correspondence to: Dr Teresa Freire, Dept. Inmunobiología, Facultad de Medicina, UdelaR, Gral. Flores 2125, 11800 Montevideo, Uruguay

E-mail: tfreire@fmed.edu.uy

Abreviations: MUC5B, mucin 5B; DCs, dendritic cells; CM, conditioned media; MUC5Bsi, MUC5B-silenced cells

Key words: mucins, cancer, MUC5B, dendritic cells

\section{Introduction}

Mucins belong to a heterogeneous group of high-molecularweight $\mathrm{O}$-glycosylated proteins that participate in the protection, lubrication, and acid resistance of the epithelial surface (1). In cancer, mucins influence cell adhesion and contribute to tumor invasiveness (2). There is a body of evidence indicating that mucins, not only constitute cancer biomarkers, but also play an active role in cancer progression by regulating cell growth, adhesion, invasion and signaling $(2,3)$. Mucins are also involved in chemo-resistance to drugs (4). Thus, the implication of mucins and their associated carbohydrate antigens in the metastatic process of tumor cells makes them relevant targets for the prevention of metastasis and recurrence of cancers by immunotherapy in combination with effective chemotherapy (5-7).

Up to date, 21 human mucins have been described and are expressed on a tissue specific basis (1). There is a variety of evidence describing the role of mucins in relation to cancer cell behavior and cell signaling pathways associated with tumorigenesis. For instance, the membrane-bound mucins MUC1 and MUC4 promote both cellular differentiation and proliferation $(2,8)$ and inhibit apoptosis (9). Similarly, secreted mucins MUC5B (10) and MUC5AC $(11,12)$ and membranebound mucins MUC13 $(13,14)$ and MUC16 $(15)$ have also been associated with aggressive behavior of cancer cells.

Mucins produced by tumor cells can also modulate tumor immunity, affecting both the innate and adaptive immune response (16). Mucin overexpression in cancer can create an immunosuppressive barrier by decreasing the accessibility of immune cells (such as NK cells) or molecules (such as complement) as well as therapeutic drugs (4). Mucins can also exert immunosuppressive roles on dendritic cells (DCs) (17). DCs are potent antigen presenting cells that possess the ability to stimulate naive $T$ cells. In response to infectious agents DCs undergo a maturation process during which they 
migrate to secondary lymphoid organs where they present captured antigens to naive T cells, for the triggering of specific immunity (18). This process is associated to an upregulation of the expression of MHC molecules, adhesion molecules and co-stimulatory molecules as well as a downregulation of their endocytotic capacity (18). Mucins, however, can modulate DC function or maturation. For instance, tumoral MUC1 is chemotactic to immature DCs, and maturation of DC in its presence subverts DC function by negatively affecting their ability to simulate type-1 helper T cell responses $(19,20)$. In other settings, mucins can, through their glycans, impair DC-maturation and antigen processing and presentation $(19,21,22)$. Indeed, we have previously shown that MUC6 carrying the tumor-associated Tn antigen impairs antigen presentation by DCs (23). Last, mucins can also induce DC death by apoptosis through interaction with Siglec-3 (24).

Among mucins, MUC5B is a secreted mucin found at high levels in the normal respiratory tract, submandibular glands, endocervix, pancreas and the hepatobiliary system $(1,25)$. MUC5B is the major mucin in the respiratory tract mucus where it is essential for mucociliary clearance that controls bacterial infection, providing protection against pathogens (26). However, MUC5B is aberrantly expressed in different cancers and may constitute a target antigen itself. Indeed, MUC5B has been detected in breast (27), gastric (28) and colon (29) adenocarcinomas, whereas it is not expressed in their respective normal tissues. Our group has reported the expression of MUC5B in breast tissues, showing that MUC5B apomucin was detected in $>80 \%$ of primary breast tumors while it was absent in normal control breast samples (27). Furthermore, the detection of MUC5B mRNA could constitute a specific marker applicable to the molecular diagnosis of breast cancer cell dissemination (30). Using different approaches we have demonstrated that the human breast cancer cell line MCF-7 expresses MUC5B (27). In this study we evaluated the role of MUC5B in breast cancer by gene silencing the MUC5B with short hairpin RNA (shRNA) using MCF-7 cells as a model.

\section{Materials and methods}

Generation of MUC5Bsi and mock MCF-7 cells. The human breast cancer cell line MCF-7 (ATCC) was cultured in complete culture medium, consisting of RPMI-1640 with glutamine (PAA Laboratories, GE Healthcare, USA) supplemented with $10 \%$ heat-inactivated fetal bovine serum (FBS), $50 \mu \mathrm{M}$ 2-mercaptoethanol, $100 \mathrm{U} / \mathrm{ml}$ penicillin, $100 \mathrm{mg} / \mathrm{ml}$ streptomycin (Sigma-Aldrich, USA), at $37^{\circ} \mathrm{C}$ and $5 \% \mathrm{CO}_{2}$. To generate the pCMV-MUC5B plasmid we amplified by PCR the CMV promoter from the pCMV-RL (Promega, USA) using primers CMV_Fw (5'-CTCACATGGCTCG ACAGATCTTCAATATTGGCC-3') and CMV_Rev (5'-GCG GGATCCTACTCTAGCCTTAAGAGCTGTAATTG-3'). The product was then digested with $B g l \mathrm{II}$ and $\mathrm{BamHI}$ and cloned at the 5' end of the eGFP coding region of peGFP-1 (BD, Biosciences, USA). The resultant plasmid was modified by PCR inserting an XhoI site at the 3'UTR region of eGFP. The shRNA directed to MUC5B was then cloned in the XhoI site using the following primers: shRNA5B_Fw (5-ATCTCGAG ATCTAGCGACCTGATCCTGTTTCTGACTAAATCGGTG AAGCCACAGATGG-3') and shRNA5B_Rev (5'-CGCTCG
AGGATCCGGCAGCCTGATCCTGTTTGACCAAATCCC ATCTGTGGCTTCACCG-3'). The shRNA5B targeted the sequence ATTTGGTCAAACAGGATCAGGC that corresponds to positions 15,534-15,552 of the mRNA of MUC5B (NM_002458.2). Presence of the inserted sequence was confirmed by sequencing. The mock cells consisted of cells transfected with the plasmid without any shRNA sequences. MCF-7 cells were transfected with the plasmids using FuGENE (Roche, France) and placed under antibiotic selection (geneticin at $0.75 \mathrm{mg} / \mathrm{ml}$ ).

Quantitative RT-PCR for MUC5B. Total cellular RNA was isolated from cells grown to $70 \%$ confluence by use of the Tri-reagent (Sigma-Aldrich) from $1-5 \times 10^{6}$ cells, according to the manufacturer's protocols. For cDNA synthesis, $5 \mu \mathrm{g}$ of total RNA was used as template in a $20-\mu$ l reverse transcription (RT) reaction using the M-MLV reverse transcriptase (Thermo Scientific Fermentas, USA) following the manufacturer's instructions. For real-time PCR, a Corbett Rotor Gene 6000 Real-Time PCR Machine and the SYBR Green 1 dye (Applied Biosystems, USA) were used according to the manufacturer's protocol. Standard amplification conditions were $3 \mathrm{~min}$ at $95^{\circ} \mathrm{C}$ and 35 cycles of $10 \mathrm{sec}$ at $95^{\circ} \mathrm{C}, 30 \mathrm{sec}$ at $52^{\circ} \mathrm{C}$, and $30 \mathrm{sec}$ at $72^{\circ} \mathrm{C}$. After each PCR reaction, the corresponding dissociation curves were analyzed to ensure that the desired amplicon was being detected and to discard contaminating DNA or primer dimers. For GAPDH detection, sense and antisense primers were 5'-TCGGAGTCAACGGATTG-3' and 5'-CCTGGAAGATGGTGATGG-3', respectively. For detection of $M U C 5 B$, sense and antisense primers were 5'-GGGCCT CGAGTGCCGTG-3' and 5'-CACACGGATTCATAGTT GAA-3', respectively, generating a 152-bp fragment. Samples were analyzed in duplicates, and product purity was checked through dissociation curves at the end of quantitative PCR (qPCR) cycles. Control reactions were performed to verify the absence of genomic DNA and cross-contamination of any other DNA source. PCR specificity was checked by melting curves, and in the case of MUC5B, the qPCR product was verified by sequencing. Relative quantity of gene expression normalized to GAPDH was analyzed with Chromas 2.4 or REST 2009 V2.0.13 software.

MUC5B expression by immunofluorescence. For immunofluorescence (IF) assays, cells were fixed for $30 \mathrm{~min}$ at room temperature with $4 \%$ paraformaldehyde in PBS. After fixation, cells were incubated for $10 \mathrm{~min}$ at room temperature with $0.05 \mathrm{M}$ ammonium chloride and permeabilized in $0.2 \%$ Triton X-100 for $1 \mathrm{~h}$ at room temperature. Then slides were incubated with a goat polyclonal anti-MUC5B IgG antibody (Y-20, Santa Cruz Biotechnology) or PBS overnight at $4^{\circ} \mathrm{C}$. After 3 washes with $0.1 \%$ Tween-20 in PBS, slides were incubated with the secondary antibody coupled to rhodamine (Pierce, USA) for $1 \mathrm{~h}$ at room temperature followed by incubation with DAPI and mounted with $80 \%$ glycerol and analyzed in a fluorescence microscope.

Cell viability assays. Cells were plated in triplicates on 96-well plates at a density of $5-160 \times 10^{3}$ cells/well. After incubation for 24,48 or 72 h, 3-(4,5 dimethyl-2 thiazolyl)-2,5 diphenyl-2H tetrazolium (MTT) bromide solution (Sigma-Aldrich) was 
added to each well, containing both adherent and non-adherent cells, at a final concentration of $0.5 \mathrm{mg} / \mathrm{ml}$ and incubated for $4 \mathrm{~h}$. The formazan crystals were dissolved in a solution containing $0.1 \mathrm{~N} \mathrm{HCl}$ in isopropanol and absorbance was measured at $570 \mathrm{~nm}$ with a plate spectrophotometer (Thermo Scientific Labsystems Multiskan). Alternatively, cells were incubated with cis-diammine-platinum dichloride (cisplatin) or 5-fluorouracil (5-FU) at $10 \mu \mathrm{g} / \mathrm{ml}$.

Evaluation of apoptosis by flow cytometry. Cells were harvested and incubated for $6 \mathrm{~h}$ in complete medium in 96 -well plates $\left(0.5 \times 10^{6}\right.$ cells $\left./ \mathrm{ml}\right)$. Then, cells (both adherent and non-adherent) were incubated with Annexin V-APC (Invitrogen, Carlsbad, CA, USA) for $30 \mathrm{~min}$ and positive cells were quantified using a CyAn ADP Analyzer (Beckman Coulter, USA). For each analysis sample a minimum of 10,000 counts were recorded.

Cell cycle analysis by flow cytometry. Mock and MUC5Bsi cells were seeded in $60-\mathrm{mm}$ Petri dishes $\left(5 \times 10^{5}\right.$ cells/dish) and cultured for $36 \mathrm{~h}$ in complete culture medium. Subsequently, the culture medium from each dish was collected and cell monolayers were then trypsinized, gently resuspended in $3 \mathrm{ml}$ of complete medium and immediately mixed with the previously collected culture medium. Cells were centrifuged (800 rpm, $5 \mathrm{~min}$ ), washed two times in $5 \mathrm{ml}$ cold PBS, fixed in cold $70 \%$ ethanol and stored at $-20^{\circ} \mathrm{C}$. Prior to flow cytometry analyses, cells were centrifuged, resuspended in 0.5 ml PBS, passed through a 50- $\mu \mathrm{m}$ nylon mesh filter, treated with $25 \mu \mathrm{l}$ RNase $(1 \mathrm{mg} / \mathrm{ml})$ and finally stained with $25 \mu \mathrm{l}$ propidium iodide (PI, $1 \mathrm{mg} / \mathrm{ml}$ ) for $10 \mathrm{~min}$. Flow cytometry cell cycle estimations were performed on a FACSVantage flow cytometer (BD Biosciences, CA, USA) equipped with a $70-\mu \mathrm{m}$ nozzle and an argon laser emitting at $488 \mathrm{~nm}(100 \mathrm{~mW})$. Fluorescence emitted from PI was collected in FL2 channel using a 575/26 band pass filter. The DNA QC Particles kit (BD Biosciences) was used to check the calibration and linearity of the equipment. Data were acquired and processed using CellQuest software (BD Biosciences). Side scatter versus forward scatter (SSC/FSC), side scatter versus FL2 pulse area (SSC/FL2-A) and FL2 pulse width versus FL2 pulse area (FL2-W/FL2-A) plots as well as FL2-A histograms were used for the analysis of DNA measurements. Experiments were performed in sextuplicate. In all cases, a total of 5,000 cells were analyzed per experimental point.

Colony forming assay. MUC5B knock-down or mock MCF-7 cells were seeded in complete media at a density of 500 cells in $10-\mathrm{cm}$ dishes. The plates were incubated at $37^{\circ} \mathrm{C}$ for two weeks and then stained with $0.1 \%$ crystal violet. Colonies of $>50$ cells were counted manually.

Cell adhesion. Ninety-six-well plates were coated with Matrigel (BD Biosciences) at $4^{\circ} \mathrm{C}$ for $8 \mathrm{~h}$ and then blocked with $1 \%(\mathrm{w} / \mathrm{v})$ bovine serum albumin at room temperature for $30 \mathrm{~min}$. Cells were trypsinized, washed with complete medium and recovered in RPMI containing 2\% FBS. Cells (5, 10 and $20 \times 10^{4}$ ) were allowed to attach for $2 \mathrm{~h}$ at $37^{\circ} \mathrm{C}$ in a humidified $5 \% \mathrm{CO}_{2}$ incubator. Attached cells were first fixed with $1 \%$ glutaraldehyde for $10 \mathrm{~min}$ at room temperature and then stained with $0.1 \%$ crystal violet for $30 \mathrm{~min}$ at room temperature. Then they were lysed with $10 \%$ acetic acid. Absorbance was read in a spectrophotometer at $570 \mathrm{~nm}$.

Preparation of tumor cell-derived conditioned media (CM). $\mathrm{CM}$ were prepared by seeding $1 \times 10^{6}$ tumor cells in $5 \mathrm{ml}$ of complete medium placed in a $25 \mathrm{~cm}^{3}$ culture flask and collected after $72 \mathrm{~h}$. The effects of CM on DCs were examined by replacing $50 \%$ of the culture medium with $\mathrm{CM}$ at the initiation of DC differentiation or maturation.

Generation of monocyte-derived DCs. PBMC were obtained following Ficoll-hypaque density-gradient centrifugation and stored in liquid nitrogen before use, as described (31). Monocytes from PBMC were purified by plastic adherence. For DC differentiation, monocytes were incubated for 2 days in RPMI supplemented with $10 \%$ (v/v) heat-inactivated FBS, $1000 \mathrm{U} / \mathrm{ml}$ GM-CSF (PeproTech, USA) and IL-4 (1\% of a conditioned supernatant from the IL-4 transfected J588L cell line). Monocyte-derived DCs were harvested and cultured in 12-well tissue culture plates for experiments. Cells with the following phenotype: $\mathrm{CD} 11 \mathrm{c}^{+} \mathrm{CD} 14^{-} \mathrm{MHC} \mathrm{II}^{\text {low }} \mathrm{CD} 86^{\text {low }}$ $\mathrm{CD} 80^{\text {low }} \mathrm{CD} 3^{\text {low }} \mathrm{CD} 40^{\text {low }}$ were considered immature $\mathrm{DC}$.

DC differentiation and maturation assays with CMs. To test the effect of CM on DC-differentiation, monocytes were cultured as described above in the presence of $50 \%$ of $\mathrm{CM}$ derived from MUC5Bsi or mock MCF-7 cells. After 2 days, medium was renewed with the same conditions and further incubated for $24 \mathrm{~h}$. Then, DCs were stimulated with LPS $(1 \mu \mathrm{g} / \mathrm{ml})$ from Escherichia coli serotype O26:B6 (Sigma-Aldrich) for $18 \mathrm{~h}$ and incubated at $37^{\circ} \mathrm{C}$ in $5 \% \mathrm{CO}_{2}$. To test the effect of $\mathrm{CM}$ on the maturation of DCs, differentiated DCs $\left(1.25 \times 10^{5}\right.$ cells/well $)$ were cultured with CM $(50 \%)$ in 12-well culture plates and incubated for $24 \mathrm{~h}$. Then, LPS $(1 \mu \mathrm{g} / \mathrm{ml})$ was added and incubated for $18 \mathrm{~h}$ at $37^{\circ} \mathrm{C}$ in $5 \% \mathrm{CO}_{2}$. Culture supernatants were collected, clarified by centrifugation and stored at $-80^{\circ} \mathrm{C}$ for a maximum period of 1 month until cytokine analysis. Monocyte-derived DCs were harvested and stained for flow cytometry analyses.

Flow cytometry and antibodies for DC staining. The following antibodies purchased from BD Biosciences were used for flow cyto-metry staining: anti-human CD86 (clone 2,331, phycoerythrin (PE)-conjugated), anti-human HLA-DR (clone TU36, fluorescein isothiocyanate (FITC)-conjugated), antihuman CD19 (clone HIB19, PE-conjugated), anti-human CD3 (clone HIT3a, FITC-conjugated), anti-human CD14 (clone M5E2, FITC-conjugated). The anti-human CD11c (clone 3.9, PerCP-eFluor ${ }^{\circledR} 710$-conjugated) was purchased from eBioscience (USA). DCs were stained and later analyzed using a $\mathrm{CyAn}^{\mathrm{TM}}$ ADP (Beckman Coulter) flow cytometer and Summit 4.3 software. For each sample the following parameters were studied: forward scatter (FSC) versus side scatter (SSC) to define the acquisition gates for intact cells, FSC versus Pulse Width dot plot were used for doublet discrimination and FSC versus FL5 channel (CD11c) for dendritic cells. For each analysed sample a minimum of 10,000 counts, gated on a FSC vs SSC dot plot, single intact DC were recorded. The median fluorescence intensity (MFI) was used to compare results. 

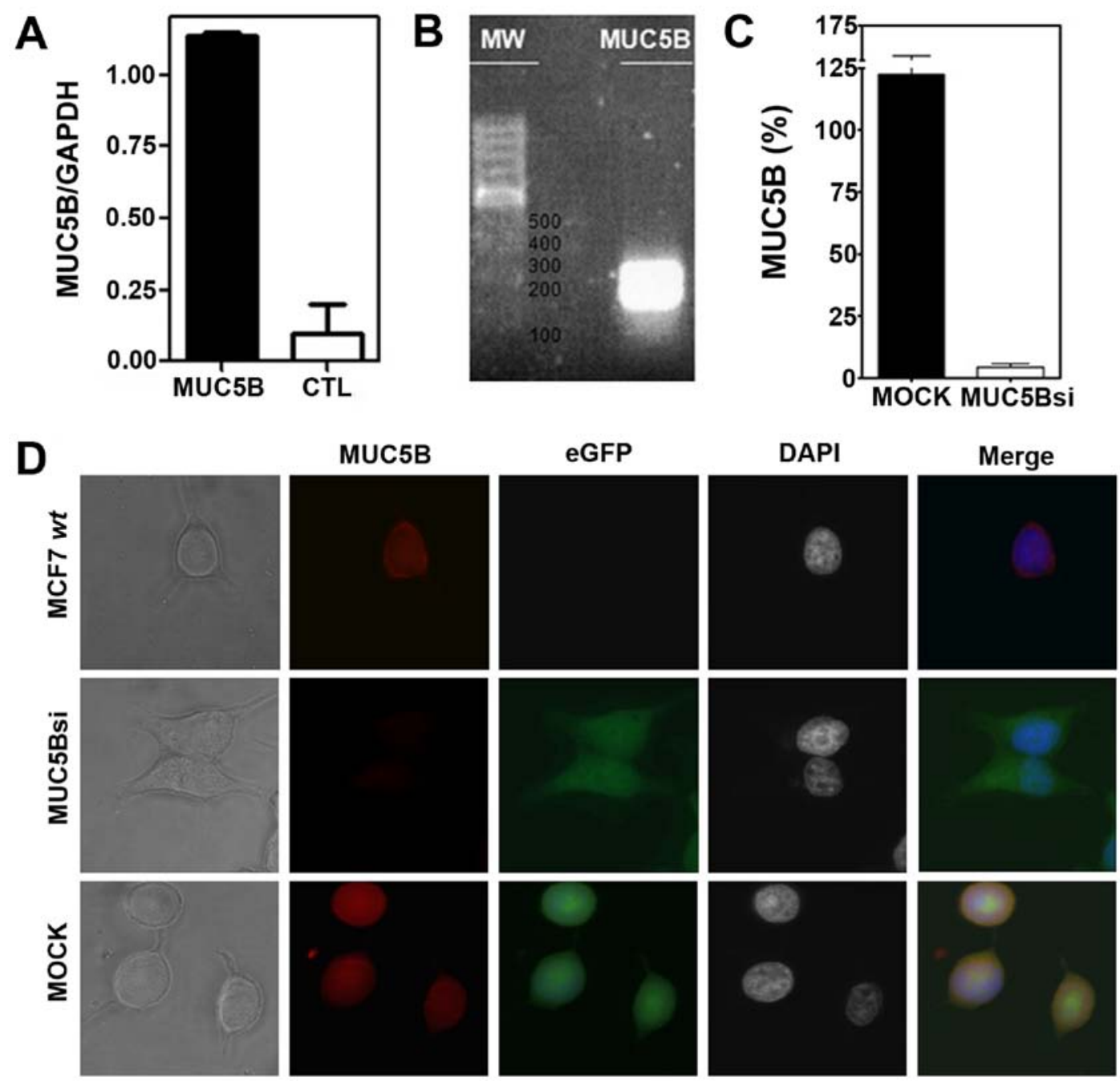

Figure 1. Generation of MUC5B-silenced and mock MCF-7 cells. (A) mRNA MUC5B expression was evaluated by qRT-PCR on MCF-7 wild-type cells using specific primers. An amplification control (CTL) without cDNA was also performed. (B) The PCR amplified mix was loaded onto a $1 \%$ agarose gel and analyzed in a UV trans-illuminator giving an amplified segment of $152 \mathrm{bp}$. (C) mRNA MUC5B was quantified on MUC5Bsi or mock MCF-7 cells by qRT-PCR, asa 100\% of the mean of MUC5B expression on MCF-7 wild-type cells. MUC5B-silenced (MUC5Bsi) cells consisted of MCF-7 cells transfected with the pCMV-MUC5B plasmid containing specific shRNA sequences as well as the coding sequences for geneticin resistance and eGFP. The mock cells consisted of cells transfected with the plasmid without any shRNA sequences. (D) Expression of MUC5B apomucin was evaluated by immunofluorescence (40X) on MUC5Bsi, mock or wild-type MCF-7 cells by incubating MCF-7 cells with a polyclonal goat anti-MUC5B antibody and then with an anti-goat conjugated to rhodamine. Nuclei were stained with DAPI. Transfected cells express the eGFP.

Cytokine measurement. IL-10, IL-6, IL-12, IL-8, TNF $\alpha$, and IL-1 $\beta$ concentrations were determined by FlowCytomix ${ }^{\mathrm{TM}}$ technology (eBioscience) and analyzed by flow cytometry. BMS FlowCytomix software version 2.2.1 was used for the analysis of the results.

Statistical analysis. Data were expressed as median and range or mean and SD, as specified. Statistic calculations were performed using the Student's t-test or two-way ANOVA with GraphPad Prism software version 5.01. Differences were considered statistically significant when the obtained value was $<0.01$ or $<0.001$.

\section{Results}

MUC5B shRNA silencing decreases cell-adhesion, cell growth and clonogenic ability of breast cancer cells. In order to evaluate the biological role of MUC5B in breast cancer, we silenced its expression in the human breast cancer cell line MCF-7, that constitutively expresses this mucin (30). The expression of MUC5B in MCF-7 cells was evaluated by qRT-PCR (Fig. 1A) and the sequence of the amplified segment (Fig. 1B) was confirmed by DNA sequencing. MUC5B expression was also evaluated by immunofluorescence on MCF-7 cells revealing a cytoplasmic and surface staining and suggesting an active biosynthesis of this mucin (Fig. 1C). To obtain a MUC5Bsilenced or knock-down clone from these cells (referred here as MUC5Bsi) we transfected them with a plasmid coding for a MUC5B-specific shRNA sequence and selected them by incubation in geneticin-containing medium. MUC5Bsi cells showed a $96 \%$ inhibition rate of MUC5B expression by qRT-PCR compared to mock cells (Fig. 1C). As expected, both transfected cells expressed the eGFP protein, while only the mock cells expressed MUC5B apomucin (Fig. 1D).

Next, we evaluated the properties of MUC5B-suppressed cells, in terms of cell growth and adhesion. MUC5Bsi cells 
A

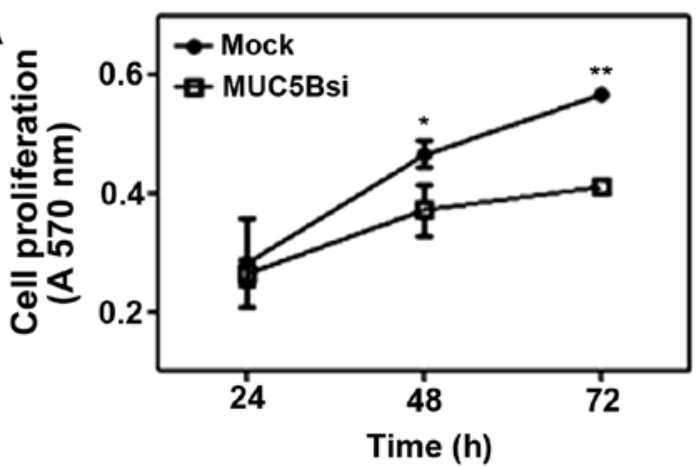

B

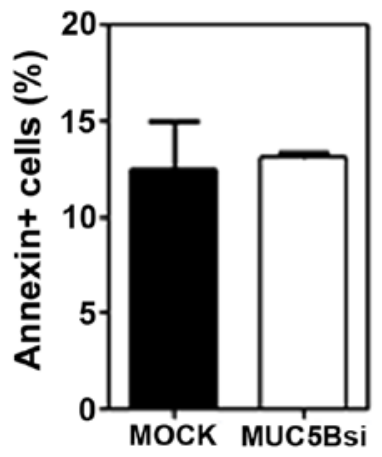

C

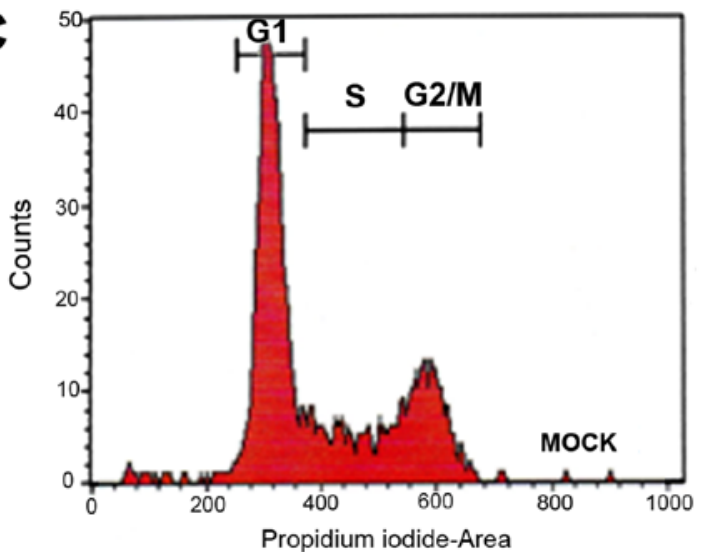

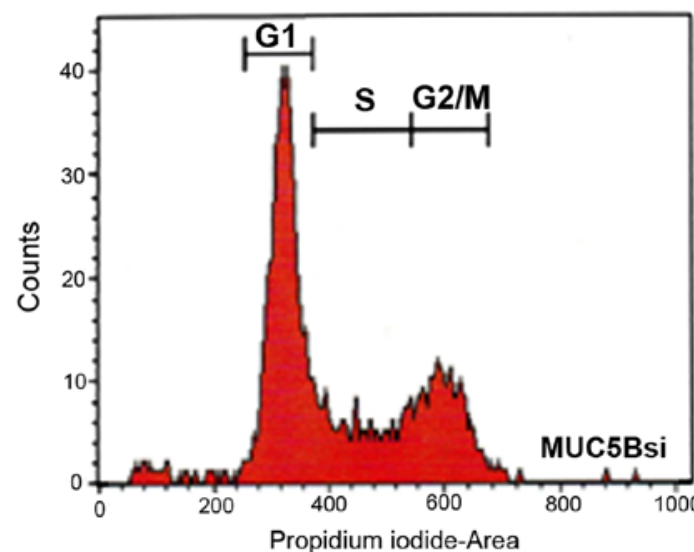

Propidium iodide-Area
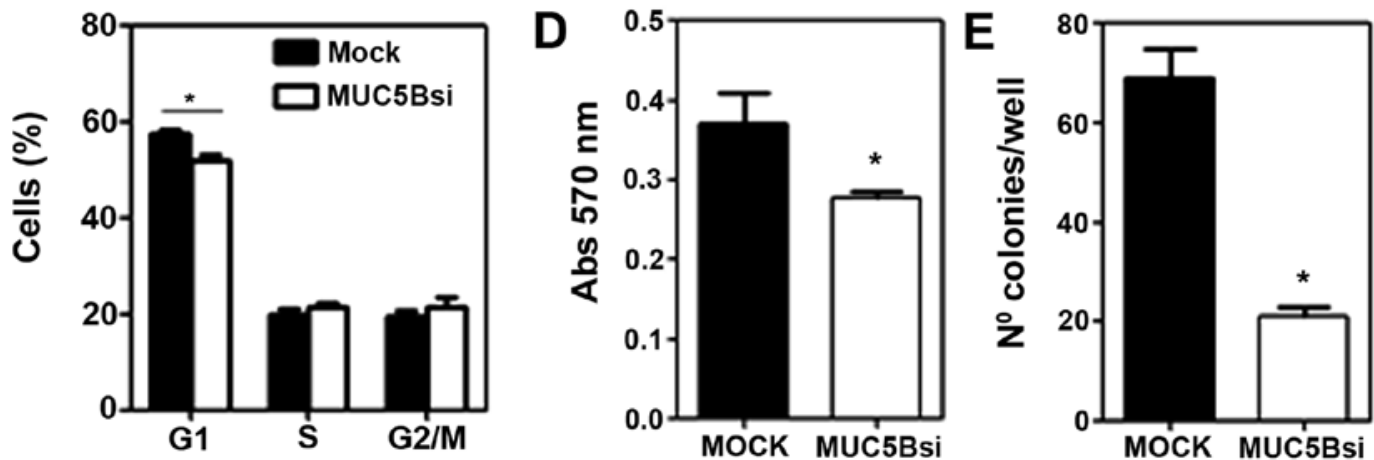

Figure 2. MUC5B silencing reduces cell growth, cell adhesion and clonogenic ability of MCF-7 cells. (A) MUC5B-silenced or mock MCF-7 cells were seeded on 96 -well plates at $5-160 \times 10^{3}$ per well and incubated at $37^{\circ} \mathrm{C}$ for 24,48 or $72 \mathrm{~h}$. Cell growth was quantified by viability with MTT. After dissolving the formazan crystals, absorbance was measured at $570 \mathrm{~nm}$. On the right results are shown as $25 \times 10^{3}$ cells per well. (B) Cells were harvested and incubated for $6 \mathrm{~h}$ in complete medium in 96-well plates $\left(0.5 \times 10^{6}\right.$ cells $\left./ \mathrm{ml}\right)$ and then incubated with Annexin V-APC. Positive cells were quantified by flow cytometry by recording 10,000 events. Apoptosis was evaluated as Annexin $\mathrm{V}^{+}$cells. (C) Mock and MUC5Bsi cells were seeded in Petri dishes, cultured for $36 \mathrm{~h}$ and stained with propidium iodide. They were then analyzed by flow cytometry to estimate cell cycle stages. (D) Cell adhesion was evaluated by coating plates with Matrigel, blocked with $1 \%$ bovine serum albumin and incubated with cells $\left(20 \times 10^{4}\right)$. Attached cells were stained with crystal violet then lysed with $10 \%$ acetic acid and absorbance was read in a spectrophotometer at $570 \mathrm{~nm}$. (E) The clonogenic ability of MUC5Bsi or mock MCF-7 cells was assayed by plating 500 cells in $10-\mathrm{cm}$ Petri dishes, cultured for 2 weeks and then cell colonies were stained with crystal violet.

showed a cell growth rate in vitro that was significantly lower than the one observed for mock cells (Fig. 3A). One possible explanation for this slowed tumor cell growth could be an increase in the steady-state levels of apoptosis of breast tumor cells or an arrest in the cell cycle. However, the downregulation of MUC5B in the breast tumor cells did not correlate to an increase in the steady-state apoptosis (Fig. 3B). On the contrary, when analyzing the percentage of mock and MUC5Bsi cells in the various phases of cell cycle, we only observed a slight decrease in the percentage of MUC5Bsi cells in the G1 phase compared to mock cells (Fig. 2C).

Suppression of MUC5B also altered the adhesive properties of breast cancer MCF-7 cells, decreasing the capacity of
MUC5Bsi cells to adhere to components of the extracellular matrix (Fig. 2D). We also evaluated the clonogenic ability of both transfected cells by plating efficiency. Cancer cells, in general, have higher plating efficiency than normal cells. MUC5Bsi cells showed a significant lower clonogenic efficiency as compared with the mock control (Fig. 2E).

Downregulation of MUC5B expression increases chemosensitivity of breast cancer cells. Different independent reports have shown that cancer cells may develop resistance to cell death induced by anticancer agents (32). To investigate whether MUC5B contributes to the resistance of breast cancer cells to chemotherapeutic drug-induced death, we exposed 
A

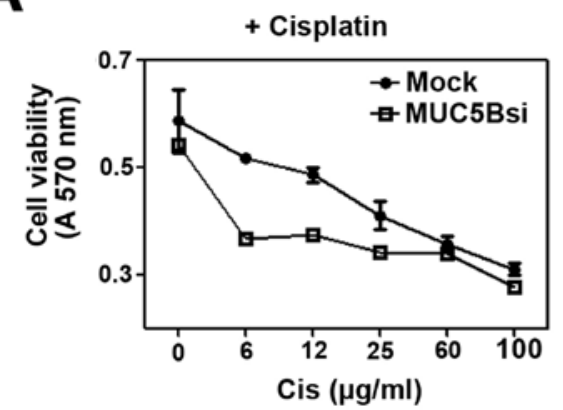

C

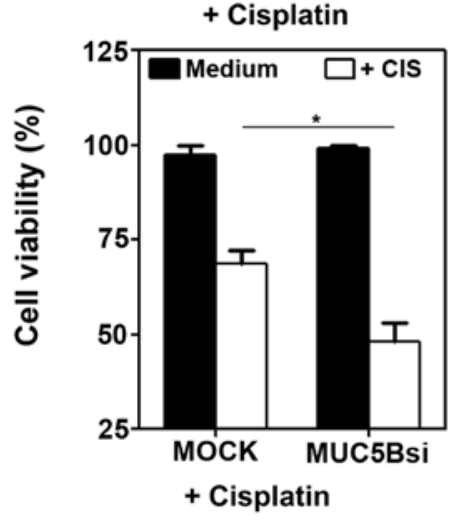

E

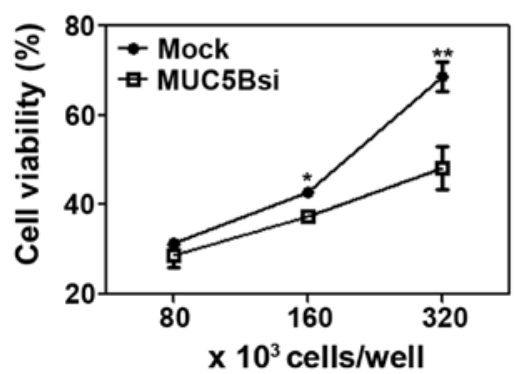

B

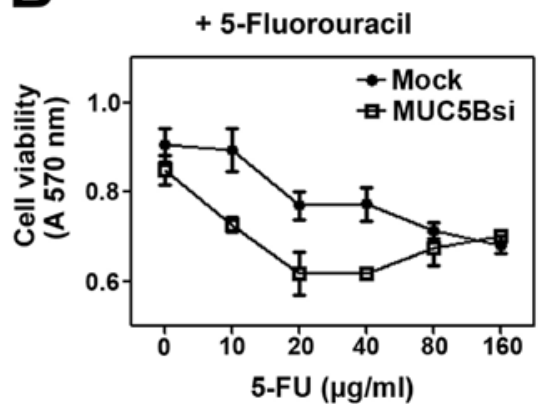

D

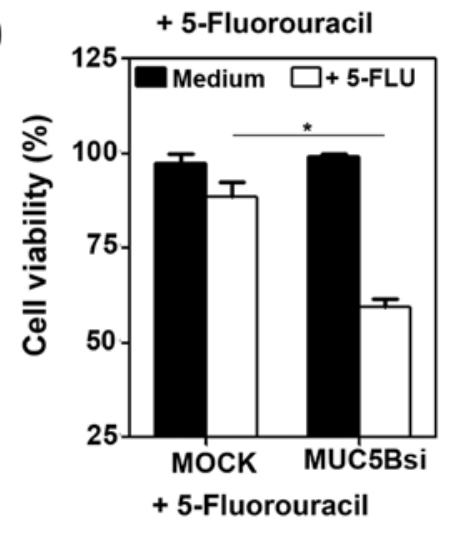

$F$

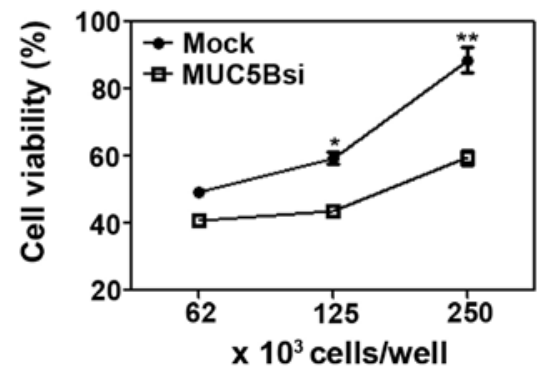

Figure 3. Downregulation of MUC5B expression increases chemo-sensitivity of MCF-7 breast cancer cells. Chemo-sensitivity to cisplatin (CIS) (A) or 5-fluorouracil (5-FU) (B) was evaluated by seeding 96-well plates with 3x10 cells/well and incubated in the presence or absence of $\mathrm{CIS}$ or 5-FU (6-160 $\mu \mathrm{g} / \mathrm{ml})$ for $48 \mathrm{~h}$ at $37^{\circ} \mathrm{C}$. Cell viability was quantified with the MTT assay. Cell viability in absence of drug was considered as $100 \%$ when CIS (C) or 5-FU (D) were used at $10 \mu \mathrm{g} / \mathrm{ml}$. Alternatively, the assay was performed with MUC5Bsi and mock cells at different cell concentrations incubated in absence or presence of $10 \mu \mathrm{g} / \mathrm{ml}$ of CIS (E) or 5-FU (F). Data are expressed as mean \pm SEM and are representative of, at least, two independent experiments. Asterisks indicate statistically significant difference with ${ }^{*} \mathrm{p}<0.01(\mathrm{~A}$ and $\mathrm{B})$ or ${ }^{* *} \mathrm{p}<0.01$ and ${ }^{*} \mathrm{p}<0.05$ (C and D).

both MUC5Bsi and mock cells to 5-fluorouracil (5-FU) or cisplatin treatment. As shown in Fig. 3, MUC5B in MCF-7 cells was associated with decreased sensitivity to 5-FU or cisplatin induced-death (Fig. 3A and B). Furthermore, MUC5Bsi cells exposed to cisplatin (at $10 \mu \mathrm{g} / \mathrm{ml}$ ) showed a 2 -fold increase in the percentage of cell death as compared to mock cells (Fig. 3C). In the same line, the percent viability with 5-FU treatment at $10 \mu \mathrm{g} / \mathrm{ml}$ for mock cells was $90 \%$, which reduced significantly to $60 \%$ in MUC5Bsi cells, indicating a 4-fold increase of cell death in MUC5B-downregulated tumor cells (Fig. 3D). The augmented chemo-sensitivity to both drugs in MUC5Bsi cells was also confirmed at different cell concentrations (Fig. 3E and F).

MUC5B expression in the culture medium enhances the production of LPS-induced cytokine levels by DCs, while MUC5B silencing impairs DC-maturation. Then, we investigated whether the silencing of MUC5B could affect the maturation of DCs, the only antigen presenting cells capable of priming naïve T cells. Although their essential role in cancer immunosurveillance (33), function of DCs can be compromised with tumor growth (34). In order to evaluate whether MUC5B silencing has an effect on the maturation of DCs we cultured them with the conditioned medium (CM) derived from MUC5Bsi or mock cells in the presence or absence of LPS. The expression of different surface molecules as well as the production of pro- and anti-inflammatory cytokines was evaluated by flow cytometry and compared to DCs incubated with CM from mock cells. Cultured DCs in presence of CM derived from tumor cells did not induce significant changes on the expression of co-stimulatory or the production of cytokines, except for the fact that incubation with $\mathrm{CM}$ from MUC5Bsi cells resulted in a decreased expression of HLA-DR (Fig. 4A).

On the contrary, when DCs were incubated in the presence of mock CM and LPS, HLA-DR expression was significantly reduced and associated to an upregulation of IL- 6 and TNF $\alpha$ (Fig. 4B). Nevertheless, when silencing MUC5B a decrease of 


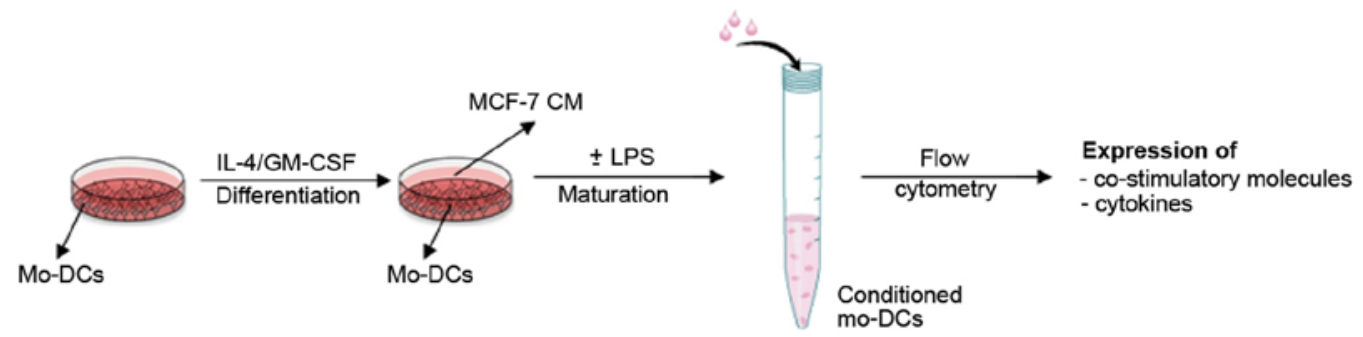

A
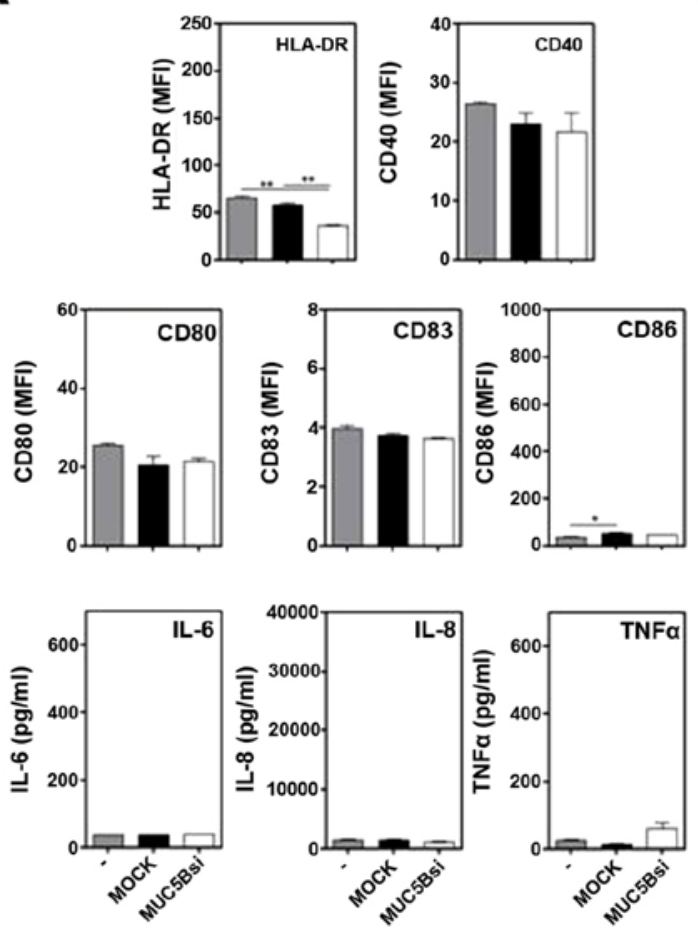

C
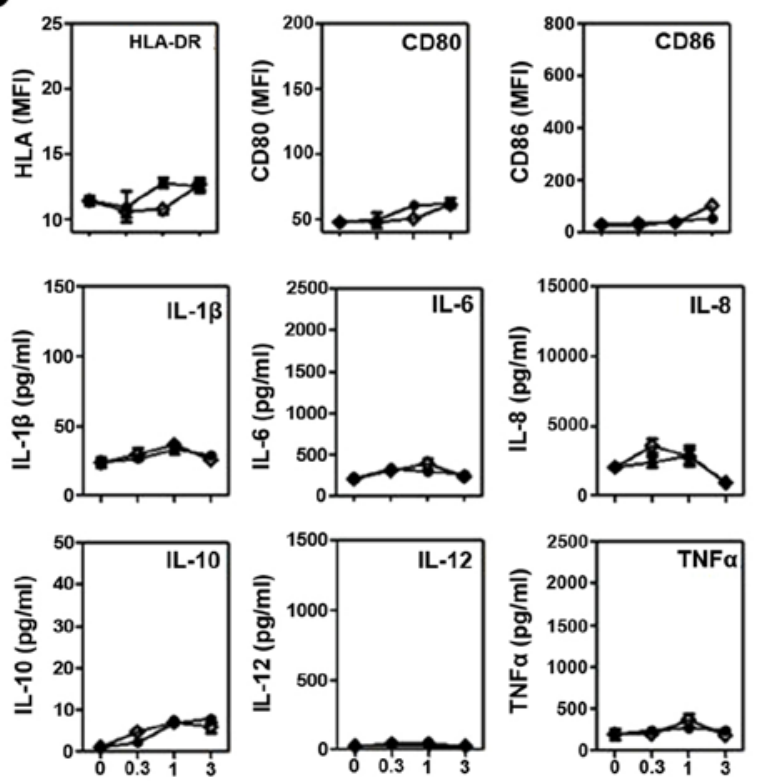

B

+ LPS
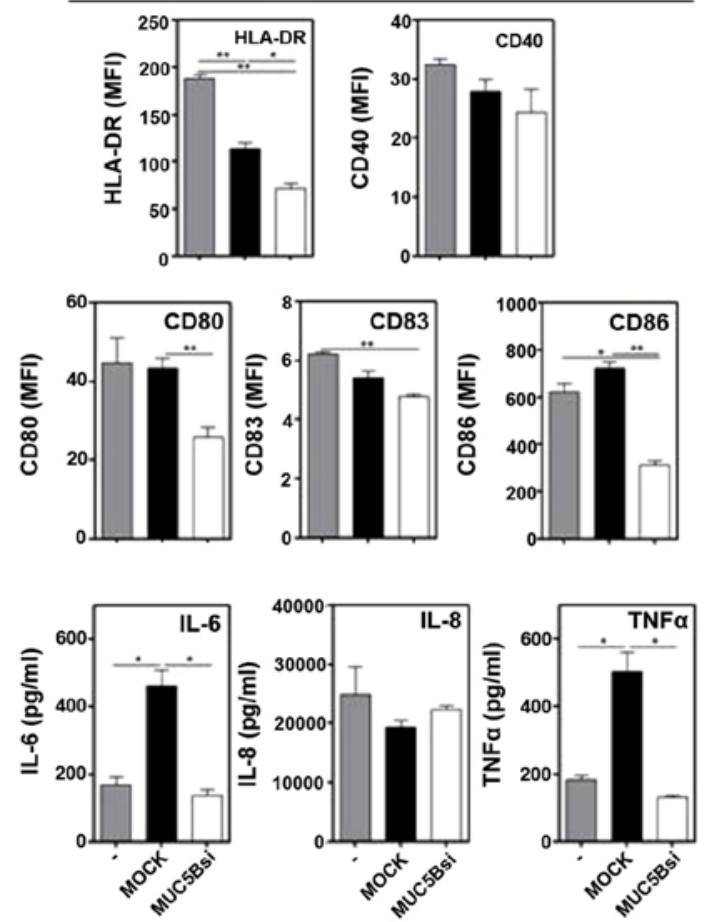

D + LPS
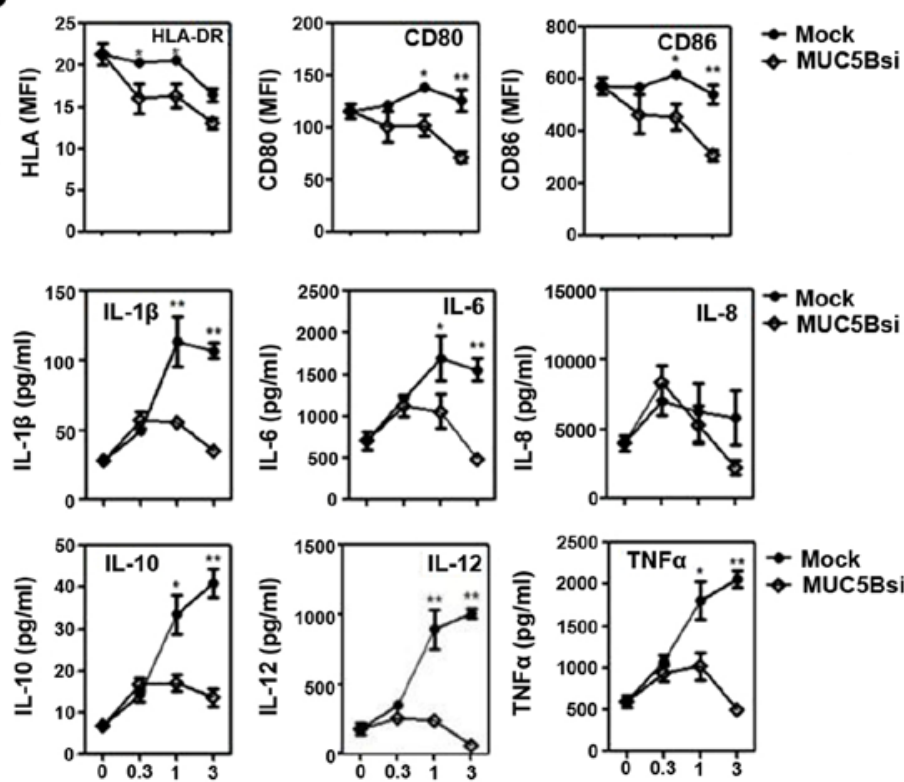

Figure 4. DCs incubated with conditioned medium (CM) from MUC5Bsi tumor cells downregulate HLA-DR, co-stimulatory molecules, as well as IL-6 and TNF $\alpha$ upon LPS stimulation. DCs were incubated with CM from MUC5Bsi or mock MCF-7 cells (ratio basal medium: CM, 1:1) in the absence (A) or presence (B) of LPS for $18 \mathrm{~h}$ at $37^{\circ} \mathrm{C}$. Expression of surface markers (HLA-DR, CD40, CD80, CD83 and CD86) and secreted cytokines (IL-6, IL-8 and TNF $\alpha$ was evaluated. Alternatively, DCs were incubated with CM from MUC5Bsi or mock MCF-7 cells (ratio basal medium:CM, 1:0, 1:0.3, 1:1 or 1:3) in the absence (C) or presence (D) of LPS. Then, cells were stained with anti-HLA-DR, CD80 or CD86 antibodies and evaluated by flow cytometry. Culture supernatants were collected for IL-1 $\beta$, IL-6, IL-8, IL-10, IL-12 and TNF $\alpha$ quantification. Data are expressed as mean \pm SD and are representative of, at least, two independent experiments performed with two different donors. Statistical differences were calculated by the Student's t-test (A and B) or the two-way ANOVA test $(\mathrm{C}$ and $\mathrm{D})\left(\mathrm{p}<0.01\right.$ and $\left.^{* *} \mathrm{p}<0.001\right)$. 


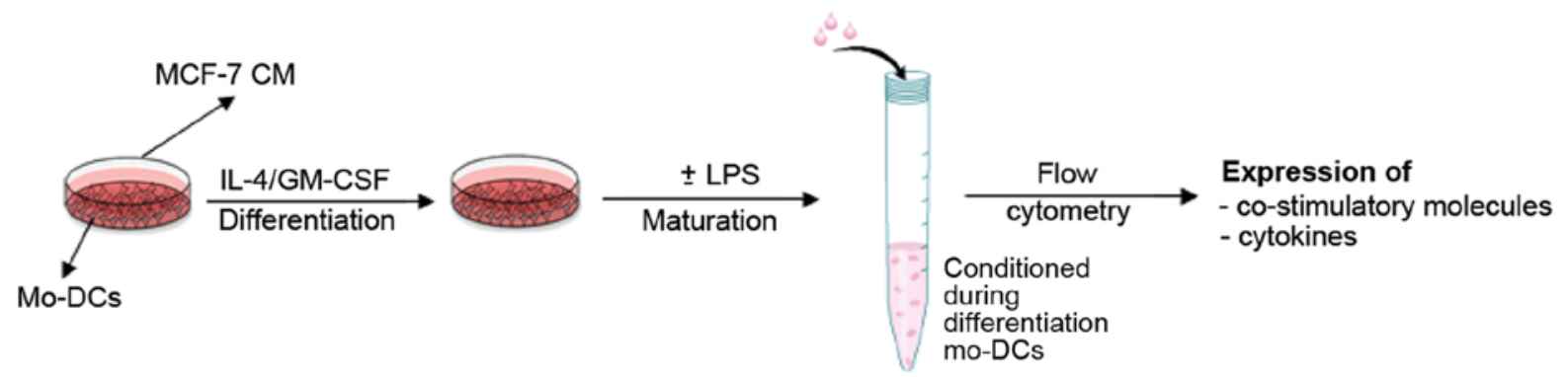

A
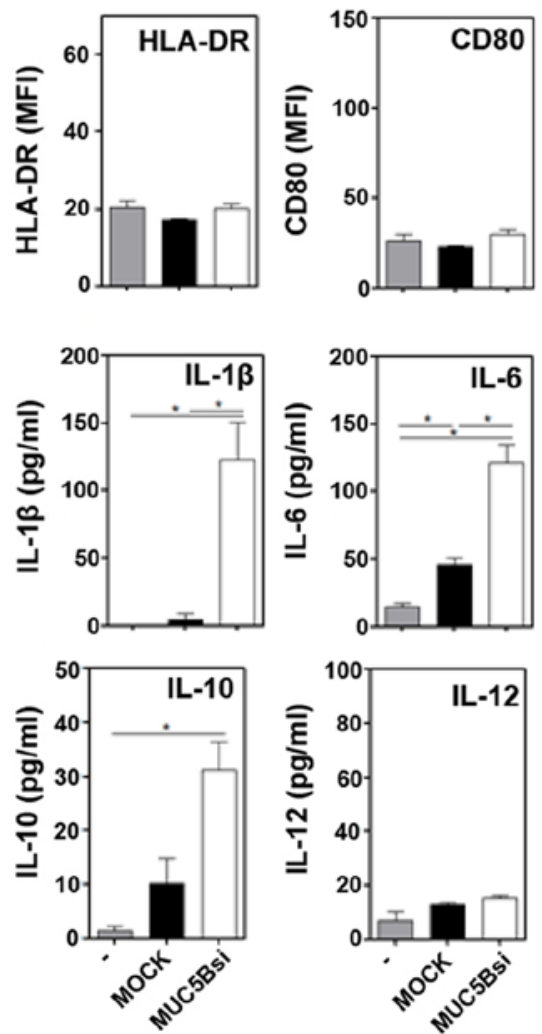

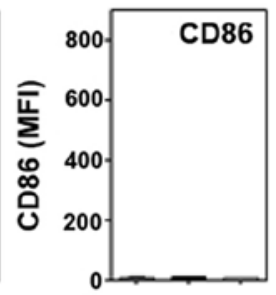

B

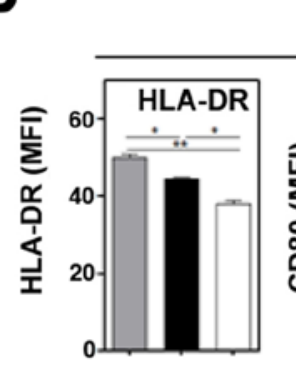

+ LPS
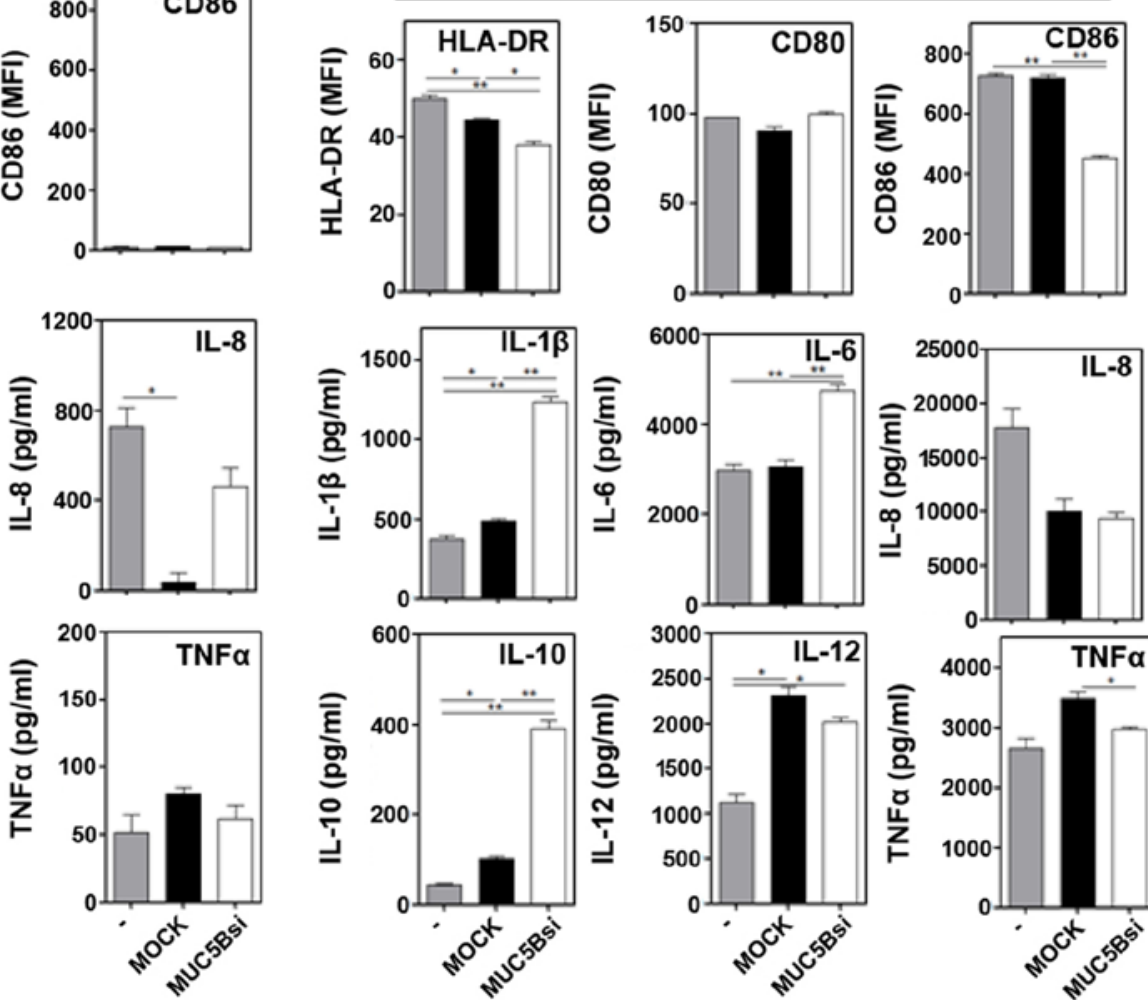

Figure 5. DCs differentiated in the presence of CM from MUC5Bsi MCF-7 cells produce higher levels of IL-1 $\beta$, IL6 and IL-10 upon stimulation to LPS as compared to mock cells. Monocytes were cultured with GM-CSF and IL-4 in the presence of CM derived from MUC5Bsi or mock MCF-7 for $48 \mathrm{~h}$ at $37^{\circ} \mathrm{C}$. Then, the medium was replaced and DCs were not stimulated (A) or stimulated with LPS (B) for $18 \mathrm{~h} \mathrm{at} 37^{\circ} \mathrm{C}$. The culture supernatants were collected for cytokine quantification and cells were stained with anti-HLA-DR, CD40, CD80 or CD86 antibodies and evaluated by flow cytometry. Data are expressed as the mean \pm SD and are representative of, at least, two independent experiments performed with two different donors. Statistically significant differences were calculated by the Student's t-test test. Asterisks indicate statistically significant difference with ${ }^{*} \mathrm{p}<0.01$ and ${ }^{* *} \mathrm{p}<0.001$.

HLA-DR, CD80, CD83 and CD86, as well as the IL-6 and TNF $\alpha$ production was observed when compared to mock cells (Fig. 4B). To further analyze the effect of CM on DCs, these experiments were carried out in the presence of different doses of CM and a broader panel of cytokines was evaluated. In the absence of a maturation stimulus we did not observe significant changes in the expression either of surface molecules or cytokines (Fig. 4C). However, in the presence of LPS and CM from mock cells, not only IL-6 and TNF $\alpha$ production was increased, but also IL-1 $\beta$, IL-10 and IL-12 levels were augmented, while IL-8 remained unchanged (Fig. 4D) and this effect was dependent on the doses of CM added. The increase in the cytokine levels was not observed with CM from MUC5Bsi cells, indicating that MUC5B silencing on MCF-7 cells significantly decreased the production of cytokines induced by MCF-7 derived-factors upon LPS stimulation. MUC5B silencing also resulted in significant decrease of HLA-DR, CD80 and CD86 by DCs incubated in presence of CM and LPS (Fig. 4D).

MUC5B silencing is associated with an increase of $I L-1 \beta, I L-6$ and $I L-10$ production by $D C s$ differentiated in the presence of tumor conditioned media. Mucins produced or shed by tumors can drain to regional lymph nodes and enter the peripheral circulation, where they could potentially modulate immune responses or differentiation of DCs (22). In order to evaluate whether MUC5B affects DC-differentiation, we incubated CM from MUC5Bsi MCF-7 cells with monocytes in the presence of GM-CSF and IL-4. After differentiation, LPS-maturation was induced, and the expression of HLA-DR and co-stimulatory molecules was evaluated by flow cytometry, as well as 
the production of a variety of cytokines. As shown in Fig. 5, DCs differentiated with CM from MUC5Bsi cells produced higher levels of IL-1 $\beta$, IL- 6 and IL-10 than DCs incubated with CM from mock cells, either in absence or presence of LPS. Interestingly, the production of IL-8 was completely abrogated when DCs were differentiated in the presence of $\mathrm{CM}$ from mock cells, while it was significantly augmented in the presence of CM from MUC5Bsi cells (Fig. 5A). In the presence of LPS, IL-8 and IL-12 expression was decreased and increased, respectively, with both CM. However, TNF $\alpha$, although augmented when DCs were differentiated in the presence of CM from mock cells, was decreased when incubated with CM from MUC5Bsi cells (Fig. 5B). Additionally, in response to LPS, the expression of HLA-DR, CD86 and TNF $\alpha$ was reduced on DCs differentiated in the presence of CM from MUC5Bsi cells as compared to incubation with $\mathrm{CM}$ from mock cells (Fig. 5B).

\section{Discussion}

An altered expression of mucin has been reported to be associated with cancer progression and can influence cell growth, differentiation, transformation, adhesion, invasion, and immune surveillance. In this study we evaluated the role of MUC5B in MCF-7 breast cancer cells by knocking down its expression with shRNA. MUC5B-silenced cells were characterized by a reduced cell growth rate, clonogenicity and capacity to adhere to components of the extracellular matrix, suggesting that MUC5B could participate in the metastatic process by providing tumor cells with a more aggressive behavior. Furthermore, the altered cell growth and adhesion did not correlate with an increase of apoptotic cells or a cell cycle arrest, suggesting that these processes might be under the control of other mechanisms. Interestingly, it has been recently reported that siRNA-mediated silencing of the secreted mucin MUC5AC on pancreatic cells led to a decrease in the expression of a set of $\alpha$ - and $\beta$-integrins (11) and the vascular endothelial growth factor (VEGF) (12), explaining at least in part, the reduced cell-adhesion and cell growth, respectively, of silenced cells (11). In this context it would be interesting to investigate whether the silencing of MUC5B in MCF-7 cells modifies the expression of these or other molecules implicated in tumor adhesion or invasion. On the other hand, the lower clonogenic efficiency of MUC5B-silenced MCF-7 cells could indicate that MUC5B silencing affected the ability of single cells to proliferate which could reduce the capacity of cancer cells to metastasize (35). Consistent with the results presented here, a previous study showed a significant increase in the growth rates of $\mathrm{MCF}-7$ cells overexpressing a recombinant form of MUC5B, compared with clones expressing endogenous amounts of MUC5B (10).

Mucins can also contribute to an augmented aggressive behavior by conferring resistance to drug-induced death. Our results show that MUC5B silencing in MCF-7 cells was associated with an increase sensitivity to 5-FU or cisplatin induced-death. In support of these findings, the ectopic overexpression of MUC4 or the knockdown of MUC1 and MUC4 on tumor cells was associated with a decreased sensitivity of these cells to various chemotherapeutic drugs (9,36-40). Since mucins are high-molecular weight glycoproteins, they could restraint the drug accessibility to the tumor cell, limiting their effectiveness in inducing cell-killing (4). The steric hindrance of membrane-bound mucins is closely linked to the number and length of $\mathrm{O}$-glycosidic chains they bear. In fact, the inhibition of O-glycosylation using benzyl$\alpha$-GalNAc both in vitro and in vivo resulted in improved antitumor effects of 5-FU $(37,41)$. A more likely mechanism that could explain the drug-resistance conferred by mucins would be through the enhancement of the expression of multi-drug resistance genes. This was described for MUC1 in pancreatic cancer cells, and found that the cytoplasmic tail motif of MUC1 was associated with the promoter region of a multi-drug resistance gene, indicating that MUC1 would act as a transcriptional regulator (42). It is more likely for MUC5B to confer chemo-resistance by reducing intracellular drug uptake and hence its antitumor drug effects, since it is a secreted mucin that could form a protection mucus web around the cell (4).

Mucins can also modulate the immune system in the benefice of tumor growth. For instance, MUC16 protects cancer cells from cytotoxic responses of natural killer cells (43), probably by interacting with the inhibitory receptor Siglec-9 (44). MUC1, on the contrary, impairs the differentiation and function of DCs $(19,22)$. For example, it has been well evidenced that tumor-derived products can selectively chemoattract immature DCs to the tumor by producing the MIP-3 $\alpha$ chemokine (17). Moreover, MUC1 produced by breast cancer cells attracts immature DCs that lack the capacity to activate Th1 cell immunity (19). Despite all the outstanding studies performed on MUC1, and to a lesser extent on MUC4 and MUC16, very few studies have focused on the elucidation of the role of secreted mucins in breast cancer, and in particular, on MUC5B. We found that MUC5Bsi-derived soluble factors impaired DC-maturation by LPS, while those from mock cells enhanced the production of LPS-induced cytokines. This could indicate that MUC5B produced by MCF-7 may induce a pro-inflammatory phenotype of DCs. However, additional experiments performed on DC conditioned with purified MUC5B are needed to establish the direct role of MUC5B on maturation of DCs. One possibility is that MUC5B interacts with DCs through its glycans, since when expressed on mucins, they can modulate immunity (45). Thus, it would be of interest to study the glycan structures carried by MUC5B produced by MCF-7 tumor cells and elucidate whether they mediate some of the effects evidenced when downregulating MUC5B. Alternatively, the silencing of MUC5B could alter the expression of other molecules that might influence DC-maturation.

Regarding the effect of mucins on DC differentiation, tumor-derived MUC1 has been shown to inhibit DC-differentiation or induce an altered function of DC differentiated in the presence of MUC1 $(20,22)$. It has been demonstrated that DC differentiated in the presence of MUC1-rich CM from pancreatic cancer cells express lower levels of MHCII and CD40 while they produce higher levels of IL-10. These treated-DCs had an impaired capacity to trigger Th1 responses and the ability to promote $\mathrm{T}$ cell regulatory activity (20). These properties have also been described for a recombinant MUC1 glycosylated protein carrying sialylated carbohydrate antigens, which impairs DC-differentiation 
and antigen presentation, through a mechanism involving MUC1 O-glycans (22). Here, we show that CM derived from MUC5Bsi MCF-7 tumor cells increases the production of IL-1 $\beta$, IL- 6 or IL-10 by DCs during their differentiation, in absence or presence of a maturation stimulus, while this was not caused by mock MCF-7 cells. In this context, it is suggested that the silencing of MUC5B could alter the expression of other molecules that could eventually be responsible for the immunomodulatory effects of MUC5Bsi CM.

In conclusion, we provide evidence showing that MUC5B expression in cancer cells contributes to certain tumorigenic properties of breast cancer cells, such as cell growth, adhesion, clonogenic ability and drug chemo-resistance, suggesting that targeting MUC5B expression by gene therapy could constitute a tool of choice in the future. On the contrary, when evaluating the effects MUC5B on differentiation and maturation of DCs, we show that MUC5B silencing impaired LPS-maturation of DCs, and production of cytokines. Furthermore, MUC5B silencing also influenced DC-differentiation since it resulted in an upregulation of IL-1 $\beta$, IL- 6 and IL-10. The immunomodulatory properties described in this study could help to develop a rational design of MUC5B-based cancer vaccines.

\section{Acknowledgements}

This study was supported by 'Comisión Honoraria de Lucha contra el Cáncer' (Uruguay), Programa Grupos de Investigación (CSIC, Universidad de la República, Uruguay) and partially financed by FOCEM (MERCOSUR Structural Convergence Fund), COF 03/11. E.P. García was supported by 'Agencia Nacional de Investigación e Innovación' and 'Comisión Académica de Posgrado' (CAP, CSIC, Uruguay). We specially acknowledge helpful advice of Dr M.G. Kramer, Dr R. Sapiro and Dr G. Peluffo.

\section{References}

1. Corfield AP: Mucins: A biologically relevant glycan barrier in mucosal protection. Biochim Biophys Acta 1850: 236-252, 2015.

2. Kufe DW: Mucins in cancer: Function, prognosis and therapy. Nat Rev Cancer 9: 874-885, 2009.

3. Rachagani S, Torres MP, Moniaux N and Batra SK: Current status of mucins in the diagnosis and therapy of cancer. Biofactors 35 : 509-527, 2009.

4. Jonckheere N, Skrypek N and Van Seuningen I: Mucins and tumor resistance to chemotherapeutic drugs. Biochim Biophys Acta 1846: 142-151, 2014.

5. Beatson RE, Taylor-Papadimitriou J and Burchell JM: MUC1 immunotherapy. Immunotherapy 2: 305-327, 2010.

6. Kimura T and Finn OJ: MUC1 immunotherapy is here to stay. Expert Opin Biol Ther 13: 35-49, 2013.

7. Häuselmann I and Borsig L: Altered tumor-cell glycosylation promotes metastasis. Front Oncol 4: 28, 2014.

8. Kaur S, Kumar S, Momi N, Sasson AR and Batra SK: Mucins in pancreatic cancer and its microenvironment. Nat Rev Gastroenterol Hepatol 10: 607-620, 2013.

9. Workman HC, Sweeney C and Carraway KL III: The membrane mucin Muc4 inhibits apoptosis induced by multiple insults via ErbB2-dependent and ErbB2-independent mechanisms. Cancer Res 69: 2845-2852, 2009.

10. Valque H, Gouyer V, Gottrand F and Desseyn JL: MUC5B leads to aggressive behavior of breast cancer MCF7 cells. PLoS One 7: e46699, 2012.

11. Hoshi H, Sawada T, Uchida M, Saito H, Iijima H, TodaAgetsuma M, Wada T, Yamazoe S, Tanaka H, Kimura K, et al: Tumor-associated MUC5AC stimulates in vivo tumorigenicity of human pancreatic cancer. Int J Oncol 38: 619-627, 2011.
12. Yamazoe S, Tanaka H, Sawada T, Amano R, Yamada N, Ohira M and Hirakawa K: RNA interference suppression of mucin 5AC (MUC5AC) reduces the adhesive and invasive capacity of human pancreatic cancer cells. J Exp Clin Cancer Res 29: 53, 2010.

13. Chauhan SC, Ebeling MC, Maher DM, Koch MD, Watanabe A, Aburatani H, Lio Y and Jaggi M: MUC13 mucin augments pancreatic tumorigenesis. Mol Cancer Ther 11: 24-33, 2012.

14. Maher DM, Gupta BK, Nagata S, Jaggi M and Chauhan SC: Mucin 13: Structure, function, and potential roles in cancer pathogenesis. Mol Cancer Res 9: 531-537, 2011.

15. Lakshmanan I, Ponnusamy MP, Das S, Chakraborty S, Haridas D, Mukhopadhyay P, Lele SM and Batra SK: MUC16 induced rapid $\mathrm{G} 2 / \mathrm{M}$ transition via interactions with JAK2 for increased proliferation and anti-apoptosis in breast cancer cells. Oncogene 31: 805-817, 2012.

16. Tinder TL, Subramani DB, Basu GD, Bradley JM, Schettini J, Million A, Skaar T and Mukherjee P: MUC1 enhances tumor progression and contributes toward immunosuppression in a mouse model of spontaneous pancreatic adenocarcinoma. J Immunol 181: 3116-3125, 2008.

17. Gottfried E, Kreutz M and Mackensen A: Tumor-induced modulation of dendritic cell function. Cytokine Growth Factor Rev 19: 65-77, 2008.

18. Steinman RM: Decisions about dendritic cells: Past, present, and future. Annu Rev Immunol 30: 1-22, 2012.

19. Carlos CA, Dong HF, Howard OM, Oppenheim JJ, Hanisch FG and Finn OJ: Human tumor antigen MUC1 is chemotactic for immature dendritic cells and elicits maturation but does not promote Th1 type immunity. J Immunol 175: 1628-1635, 2005.

20. Monti P, Leone BE, Zerbi A, Balzano G, Cainarca S, Sordi V, Pontillo M, Mercalli A, Di Carlo V, Allavena P, et al: Tumorderived MUC1 mucins interact with differentiating monocytes and induce IL-10highIL-12low regulatory dendritic cell. J Immunol 172: 7341-7349, 2004.

21. Hiltbold EM, Vlad AM, Ciborowski P, Watkins SC and Finn OJ: The mechanism of unresponsiveness to circulating tumor antigen MUC1 is a block in intracellular sorting and processing by dendritic cells. J Immunol 165: 3730-3741, 2000.

22. Rughetti A, Pellicciotta I, Biffoni M, Bäckström M, Link T, Bennet EP, Clausen H, Noll T, Hansson GC, Burchell JM, et al: Recombinant tumor-associated MUC1 glycoprotein impairs the differentiation and function of dendritic cells. J Immunol 174: 7764-7772, 2005.

23. Freire T, Lo-Man R, Bay S and Leclerc C: Tn glycosylation of the MUC6 protein modulates its immunogenicity and promotes the induction of Th17-biased T cell responses. J Biol Chem 286: 7797-7811, 2011.

24. Ishida A, Ohta M, Toda M, Murata T, Usui T, Akita K, Inoue M and Nakada H: Mucin-induced apoptosis of monocyte-derived dendritic cells during maturation. Proteomics 8: 3342-3349, 2008.

25. Andrianifahanana M, Moniaux N and Batra SK: Regulation of mucin expression: Mechanistic aspects and implications for cancer and inflammatory diseases. Biochim Biophys Acta 1765: 189-222, 2006.

26. Roy MG, Livraghi-Butrico A, Fletcher AA, McElwee MM, Evans SE, Boerner RM, Alexander SN, Bellinghausen LK, Song AS, Petrova YM, et al: Muc5b is required for airway defence. Nature 505: 412-416, 2014.

27. Sóñora C, Mazal D, Berois N, Buisine MP, Ubillos L, Varangot M, Barrios E, Carzoglio J, Aubert JP and Osinaga E: Immunohistochemical analysis of MUC5B apomucin expression in breast cancer and non-malignant breast tissues. J Histochem Cytochem 54: 289-299, 2006.

28. Buisine MP, Devisme L, Degand P, Dieu MC, Gosselin B, Copin MC, Aubert JP and Porchet N: Developmental mucin gene expression in the gastroduodenal tract and accessory digestive glands. II. Duodenum and liver, gallbladder, and pancreas. J Histochem Cytochem 48: 1667-1676, 2000.

29. Walsh MD, Clendenning M, Williamson E, Pearson SA, Walters RJ, Nagler B, Packenas D, Win AK, Hopper JL, Jenkins MA, et al: Expression of MUC2, MUC5AC, MUC5B, and MUC6 mucins in colorectal cancers and their association with the $\mathrm{CpG}$ island methylator phenotype. Mod Pathol 26: 1642-1656, 2013.

30. Berois N, Varangot M, Sóñora C, Zarantonelli L, Pressa C, Laviña R, Rodríguez JL, Delgado F, Porchet N, Aubert JP, et al: Detection of bone marrow-disseminated breast cancer cells using an RT-PCR assay of MUC5B mRNA. Int J Cancer 103: 550-555, 2003. 
31. Tiscornia I, Sánchez-Martins V, Hernández A and BollatiFogolín M: Human monocyte-derived dendritic cells from leukoreduction system chambers after plateletpheresis are functional in an in vitro co-culture assay with intestinal epithelial cells. J Immunol Methods 384: 164-170, 2012.

32. Lu HP and Chao CC: Cancer cells acquire resistance to anticancer drugs: An update. Biomed J 35: 464-472, 2012.

33. Anguille S, Smits EL, Lion E, van Tendeloo VF and Berneman ZN: Clinical use of dendritic cells for cancer therapy. Lancet Oncol 15: e257-e267, 2014.

34. Hegmans JP and Aerts JG: Immunomodulation in cancer. Curr Opin Pharmacol 17: 17-21, 2014.

35. Pandit TS, Kennette W, Mackenzie L, Zhang G, Al-Katib W, Andrews J, Vantyghem SA, Ormond DG, Allan AL, Rodenhiser DI, et al: Lymphatic metastasis of breast cancer cells is associated with differential gene expression profiles that predict cancer stem cell-like properties and the ability to survive, establish and grow in a foreign environment. Int $\mathbf{J}$ Oncol 35: 297-308, 2009.

36. Mimeault M, Johansson SL, Senapati S, Momi N, Chakraborty S and Batra SK: MUC4 down-regulation reverses chemoresistance of pancreatic cancer stem/progenitor cells and their progenies Cancer Lett 295: 69-84, 2010.

37. Kalra AV and Campbell RB: Mucin impedes cytotoxic effect of 5-FU against growth of human pancreatic cancer cells: Overcoming cellular barriers for therapeutic gain. Br J Cancer 97: 910-918, 2007.

38. Ren J, Agata N, Chen D, Li Y, Yu WH, Huang L, Raina D, Chen W, Kharbanda S and Kufe D: Human MUC1 carcinomaassociated protein confers resistance to genotoxic anticancer agents. Cancer Cell 5: 163-175, 2004.
39. Siragusa M, Zerilli M, Iovino F, Francipane MG, Lombardo Y, Ricci-Vitiani L, Di Gesù G, Todaro M, De Maria R and Stassi G: MUC1 oncoprotein promotes refractoriness to chemotherapy in thyroid cancer cells. Cancer Res 67: 5522-5530, 2007.

40. Skrypek N, Duchêne B, Hebbar M, Leteurtre E, van Seuningen I and Jonckheere N: The MUC4 mucin mediates gemcitabine resistance of human pancreatic cancer cells via the Concentrative Nucleoside Transporter family. Oncogene 32: 1714-1723, 2013.

41. Kalra AV and Campbell RB: Mucin overexpression limits the effectiveness of 5-FU by reducing intracellular drug uptake and antineoplastic drug effects in pancreatic tumours. Eur J Cancer 45: 164-173, 2009.

42. Nath S, Daneshvar K, Roy LD, Grover P, Kidiyoor A, Mosley L, Sahraei M and Mukherjee P: MUC1 induces drug resistance in pancreatic cancer cells via upregulation of multidrug resistance genes. Oncogenesis 2: e51, 2013.

43. Patankar MS, Jing Y, Morrison JC, Belisle JA, Lattanzio FA, Deng Y, Wong NK, Morris HR, Dell A and Clark GF: Potent suppression of natural killer cell response mediated by the ovarian tumor marker CA125. Gynecol Oncol 99: 704-713, 2005.

44. Belisle JA, Horibata S, Jennifer GA, Petrie S, Kapur A, André S, Gabius HJ, Rancourt C, Connor J, Paulson JC, et al: Identification of Siglec-9 as the receptor for MUC16 on human NK cells, B cells, and monocytes. Mol Cancer 9: 118, 2010.

45. Freire T and Osinaga E: The sweet side of tumor immunotherapy. Immunotherapy 4: 719-734, 2012. 